\title{
The Non-Coding RNAs Involved in Physiology and Pathology of Skin Melanocyte and Melanoma
}

\author{
Ren $H^{1,3}$, Chen $X^{2}$, Wang $G^{1,3}$, Sun $X^{1,3}$, Jiang $J^{1,3}$, Zhang $L^{1,3}$, Dong \\ $\mathrm{X}^{1,3}$, Li J1,3, Fu L1,3, Zhou P1,3, Wu Y2 and Song T2* \\ ${ }^{1}$ Chongqing Academy of Animal Sciences, China \\ ${ }^{2}$ Institute of Animal Science, China \\ ${ }^{3}$ Chongqing Engineering Research Center for Goats, China
}

\section{Review Article}

Volume 2 Issue 6

Received Date: November 18, 2019

Published Date: December 04, 2019

DOI: $10.23880 /$ izab-16000188

*Corresponding author: Tianzeng Song, Institute of Animal Science, Tibet Academy of Agricultural and Animal Husbandry Sciences, Tibet, Lhasa, 850000, China, Email: songtianzeng123@sina.com

\begin{abstract}
The non-coding RNAs consist of the major of transcripts in genome in higher plants and animals, and they modulate gene expression at multiple levels to affect the growth, development, physiology, and disease in organisms. Recent findings demonstrate that the non-coding RNAs play important roles in physiology and pathology of melanocyte and melanoma. We reviewed the progress in non-coding RNAs (microRNA and long non-coding RNA) involved in pigmentation to provide insights into the melanocyte and melanoma biology.
\end{abstract}

Keywords: Micro RNA; Long Non-Coding RNA; Melanocyte; Melanoma

\section{Category of Noncoding RNAs}

Noncoding RNAs (ncRNAs) are those transcribed but not translated into proteins. According to their function, they are classified into housekeeping RNAs including ribosomal(rRNA), transfer RNA (tRNA), small nuclear RNA(snRNA), small nucleolar RNA(snoRNA), transfermessenger RNA(tmRNA), guide RNA(gRNA), telomerase RNA and regulatory RNAs such as microRNA(miRNA), piwi-interacting RNA(piRNA), small interfering RNA(siRNA), enhancer RNA(eRNA), long noncoding RNA(lncRNA), circle RNA(cRNA). Alternatively, based on their length, they are also classified into small RNAs (18 to 200 nucleotides) and long RNAs (>200 nucleotides). Among the ncRNAs, miRNA is one group that has been identified earliest and most extensively studied [1-4]. Subsequently, piRNA, which is a class of animal germ cell specific and single stranded RNA molecule (24 to 30 nucleotides), has been found $[5,6]$. However, the first discovered lncRNAs are H19 and XIST [7-10]. With evolution of species, the count of ncRNA, especially for miRNA and IncRNA, would be increasing as well. In addition, with development of investigation, the biological mechanism of ncRNAs in genome is expanding and enriching as well. Taking miRNA as example, it has been traditionally regarded as negative regulator of gene expression by binding to the $3^{\prime}$ untranslated region of a target mRNA, leading to translational inhibition or degradation of protein-coding genes. However, recent evidence shows that miRNA can target various 


\section{International Journal of Zoology and Animal Biology}

noncanonical sites such as DNA promoter regions, RNA 5' untranslated region, other ncRNAs, and proteins, which is far beyond that initially thought. More interestingly, miRNAs can promote protein translational either directly via recruitment of protein complexes, or indirectly unleashing the translation repression. For example, miRNAs can modulate the Toll-like receptor signaling by an agonist effect on Toll-like receptors [11]. It is acknowledged that the ncRNAs are master regulators of transcription, transcript stability, and translation of protein-coding transcripts, with roles in both physiological and pathological processes.

\section{Melanocytes Development and Melanoma}

Melanocytes originate from the neural crest with pluripotential cells that gradually become lineage specific during development [12,13], eventually they become localized in hair follicles as well as in the epidermis to pigment the hair and skin, respectively [14]. It is known that melanocyte is not only responsible for synthesis of different types of pigment in melanosomes, but also for the transport of pigment from melanocyte to the surrounding epithelial cell (keratinocyte). Melanins can be produced in two chemically distinct types, black-tobrown eumelanin and yellow-to-reddish-brown pheomelanin by the melanocyte in mammal and bird. In nature, many biological systems produce a combination of the two types of melanin. The extracellular signals control the type of melanin produced by melanocyte including ASIP/ $\alpha-M S H / M C 1 R, \quad$ SCF/c-Kit, ET-1/ETBR, Wnt/ $\beta-$ catenin, bFGF/FGFR, HGF-cMET, GM-CSF/GM-CSFR, PGs/PGR, NGF/NGFR, LIF/gp130LIFR $\alpha, D K K 1 / L R P$, TGF 1 1/T $\beta R$, NO/cGMP, and sex hormones (i.e., androgen, estrogen) pathways [15]. Defects in melanocyte development and function are associated with a variety of human diseases and disorders, whereas the cancerous growth of melanocytes can results in melanoma. Melanoma is one of the most aggressive human skin cancer and some sub-type is highly resistant to treatment. Until now, there are more than 378 loci in mouse (171 cloned and 207 uncloned genes) involved in tissue pigmentation (http://www.espcr.org/micemut/), of which transcription factors such as MITF, PAX3, and SOX10 play crucial regulatory roles in cell commitment, migration, survival, and differentiation of the melanocyte
[16]. Besides the above protein-coding genes already described, recent evidence indicates that non-coding RNAs, such as micro RNA and long noncoding RNA, play crucial roles in melanocyte and melanoma biology.

\section{MicroRNAs}

Since Wu, et al. [17] for the first time reported the role of miR-434-5p in regulation of human skin color, a large number of miRNAs related to melanogenesis have been identified. Recently, Mione, et al. [18], Mirzaei, et al. [19], Ross, et al. [20] made comprehensive reviews about the role of miRNAs in melanogenic process. For example, one group of miRNAs including miR-15b, miR-21, miR-99a, miR-137, miR-145, miR-148, miR-149, miR-193b, miR194, miR-203, miR-205, miR-206,miR-211,miR221/22,miR-214,let-7a/b,miR-506-514 and so on are involved in cell growth and proliferation. The other group of miRNAs including miR-18b,miR-26a,miR-34a,miR34b/c,miR-100,miR-155, miR-125b,miR-137,miR-

149,miR-203,miR-4286, miR-205, et al. participate in cell apoptosis. Another group of miRNAs such as miR214,miR-30b/30d,miR-182,miR-126,miR-137,miR-

196a,miR-18b,miR-34b/c,miR-199, miR-211,miR-9, miR31 , et al. are related to cell survival, invasion and metastasis. However, most of these reports are derived from the melanoma in human, few studies are conducted in normal melanocyte. Recently, there are only 3 miRNAs (miR-155 [21], miR-9 [22], miR-2909 [23]) identified in human melanocytes. Findings from Dong $\mathrm{C}$ and his colleagues in ShanXi Agricultural University found miR25, miR-101a-3p, miR-144a-3p, lpa-miR-nov-66, miR143-5p, and miR-5110 play important roles in alpaca melanocyte migration, proliferation and melanogenesis [24-28]. Zhang, et al. [29] identified a miRNA in embryonic chicken retinal pigment epithelium and showed that the protective effects of alpha-MSH may be due to the MC4R mediated-down-regulation of miR-194 during the glutamate-induced excite toxicity. Our team have recently identified some miRNA involved in skin pigmentation in goat, such as miR-381, miR-543, miR544, miR-129, and miR-29a [30,31]. We summaries these studies in Table 1, which can contribute with a better knowledge about microRNAs involved in epigenetic regulation of melanogenesis.
Song $\mathrm{T}$, et al. The Non-Coding RNAs Involved in Physiology and Pathology of Skin Melanocyte and Melanoma. Int J Zoo Animal Biol 2019, 2(6): 000188.
Copyright@ Song T, et al. 


\section{International Journal of Zoology and Animal Biology}

\begin{tabular}{|c|c|c|}
\hline miRNAs & Roles in cell process & Cell source \\
\hline $\begin{array}{l}\text { miR-10b[32-55],miR-15b, miR-18a-5p, miR-21, miR-99a, miR-106a, miR- } \\
\text { 137, miR-145-5p, miR-148, miR-149, miR-193b, miR-194, miR-203, miR-205, } \\
\text { miR-206, miR-211, miR-221, miR-222, miR-214, let-7a/b/c, and miR-506- } \\
\text { 514, miR-140-5p, miR-150-5p, miR-154, miR-431, miR-142, miR-146a, miR- } \\
\text { 217, miR-224-5p, miR-136, miR-135b, anti-miR-1297, miR-28-5p, miR-495- } \\
\text { 3p, miR-1224-5p, miR-1297, miR-155, miR-126-3p, miR-507 }\end{array}$ & $\begin{array}{l}\text { cell growth and } \\
\text { proliferation }\end{array}$ & melanoma \\
\hline $\begin{array}{l}\text { miR-18b,miR-26a-5p[56,57],miR-34a,miR-34b/c,miR-100, miR-150-5p[42], } \\
\text { miR-155,miR-125b,miR-137,miR-149,miR-203, miR-4286, and miR-205, } \\
\text { miR-126[58], miR-494[59], miR-590-5p[60-62], miR-383, miR-497-5p, miR- } \\
\text { 195-5p and miR-455-3p }\end{array}$ & cell apoptosis & $\begin{array}{l}\text { Melanoma, retinal } \\
\text { pigment epithelia }\end{array}$ \\
\hline $\begin{array}{l}\text { let-7b/c[39], miR-10b[32,63], miR-18a-5p,miR-214,miR-30b/30d,miR-182, } \\
\text { miR-137,miR-196a,miR-18b,miR-34b/c,miR-199,miR-211[36],miR-9, and } \\
\text { miR-31, miR-140-5p, miR-150-5p[41], miR-154[43-45], miR-431, miR-142, } \\
\text { miR-146a, miR-150-5p[42], miR-224-5p[48], miR-136[49], miR-135b[50], } \\
\text { miR-28-5p[51], miR-199a-3p[64], miR-122-5p[65], miR-455-5p, miR-495- } \\
\text { 3p, miR-1224-5p[66], miR-145-5p[35], miR-222[37], miR-205[67], miR-126- } \\
\text { 3p[54], miR-507[55] }\end{array}$ & $\begin{array}{l}\text { ell survival, migration } \\
\text { invasion, and } \\
\text { metastasis }\end{array}$ & melanoma \\
\hline miR-625-5p[68] & $\begin{array}{l}\text { melanoma cell } \\
\text { glycolysis }\end{array}$ & melanoma \\
\hline $\begin{array}{l}\text { miR-25[24], lpa-miR-nov-66[26], miR-143-5p[27], miR-5110[25], miR- } \\
\text { 101a-3p and miR-144a-3p[28] }\end{array}$ & $\begin{array}{c}\text { melanocyte migration, } \\
\text { proliferation }\end{array}$ & $\begin{array}{l}\text { Alpaca skin } \\
\text { melanocytes }\end{array}$ \\
\hline miR-155[21], miR-9[22], miR-2909[23] & $\begin{array}{c}\text { cell survival, adhesion } \\
\text { migration, } \\
\text { mitochondrial } \\
\text { respiration }\end{array}$ & $\begin{array}{c}\text { human primary } \\
\text { melanocytes }\end{array}$ \\
\hline $\operatorname{miR}-194[29]$ & $\begin{array}{c}\text { cell death and tissue } \\
\text { damage }\end{array}$ & \begin{tabular}{c|} 
embryonic \\
chicken retinal \\
pigment \\
epithelium \\
\end{tabular} \\
\hline miR-381[30],miR-543[30], miR-544[30], miR-129[30], miR-29-5p[31] & \begin{tabular}{|c|} 
melanogenesis, \\
melanocyte migration
\end{tabular} & $\begin{array}{c}\text { goat skin } \\
\text { melanocytes }\end{array}$ \\
\hline
\end{tabular}

Table 1: The category of microRNAs based on their roles in melanocyte and melanoma cell.

\section{Long Non-Coding RNAs}

There is a body growing of evidence which suggests that the long non-coding RNAs (lncRNAs) play important roles in modulation of melanocyte biology. In order to explore the molecular mechanism underlying the early skin pigmentation, we identified recently a large number of skin lncRNAs associated with melanogenesis by Illumina RNA sequencing in two different color of fetal skin in goats and investigated their basic characteristics and the genome-wide cis-/trans- actions [69]. However most of database of IncRNAs already described as involved in pigment as deposited in human melanoma database. Based on the mechanisms underpinning the regulation of melanogenesis, we classify them into two groups. Some lncRNAs affect melanoma occurrence and invasion, and melanoma cell behavior through modulation of the protein-coding genes, such as GAS5 [70], NUMB [71], PAUPAR [72], SAMMSON [73], SLNCR1 [74], ANRIL [75], CANT1 [76], PVT1 [77], HOXD-AS1[78], MT1JP[79], TUSC7[80], LINC01260 [81], H19 [82], MEG3 [83], ILF3-AS1 [84], GAS5 [85], RMEL3 [86], SNHG7 [87], NEAT1 [88], SNHG17 [89], HAND2-AS1 [90], SLNCR [91], MIAT [92]. For example, the results of Li, et al. [83] suggested that MEG3 can inhibit melanoma development through blocking Wnt signaling pathway. Schmidt, et al. [91] demonstrated that SLNCR recruits AR to EGR1bound genomic loci and switches EGR1-mediated 
transcriptional activation to repression of the tumor suppressor p21(Waf1/Cip1), which implicate the regulatory triad of SLNCR, AR, and EGR1 in promoting oncogenesis and may help explain why men have a higher incidence of and more rapidly progressive melanomas compared with women.

Others of lncRNAs function as a sponge competing endogenous RNA (ceRNA) for miRNA, such as UCA1 [51, 55], HOXA11-AS [93], CCAT1 [94], MALAT1 [57,95], MEG3 [96], ATB [60], CASC2 [33], SNHG5 [56], NEAT1 [97], TUG1 [98], ZEB1-AS1 [66], OIP5-AS1 [47], ZFAS1 [42], DSCAM-AS1 [49], FOXD3-AS1 [99], MIR205HG [100], MIAT [100], and AK077216 [61]. For example, Lu, et al. [93] demonstrated that HOXA11-AS, which is overexpressed in UM tissues and cells, could simultaneously interact with enhancer of zeste homolog 2 (EZH2) to suppress its target p21 protein expression. HOXA11-AS also functioned as a molecular sponge for miR-124, and overexpression of miR-124 attenuated the proliferation and invasion-promoting effect of HOXA11AS. In addition, Wang, et al. [101] identified 5 candidate ceRNA(AC068594.1， C7orf71， FAM41C, GPC5-AS1, MUC19, LINC00402) by integrative analysis of IncRNAs, miRNA and mRNA expression in metastatic melanoma.
Like the relationship between miRNA and mRNA, a IncRNA can act as a sponge for two miRNAs simultaneously, such as UCA1 vs. miR-28-5p and miR-507 [51,55], MALAT1 vs. miR-34a and miR-183 [57,95]. Interestingly, some lncRNA can act as a positive regulator of microRNA but not as a microRNA sponge in regulation of melanocyte biology. For example, Cheng, et al. [37] found miR-222 is positively regulated by HMGA1. Moreover, the proliferation and migration of UM cells significantly increased in the miR-222 mimics group and decreased in the miR-222 inhibitor group. The p-PI3K, pAkt and MMP9 expressions were elevated in UM cells transfected with miR-222 mimics, and suppressed in the miR-222 inhibitor group. In addition, there is an interaction between two IncRNAs in melanoma. For example, Huang, et al. [102] revealed that lncRNA LINCPINT is down regulated in melanoma and may regulate melanoma cell proliferation by down regulating IncRNA BANCR. These studies substantially enlarge the function profiles of lncRNAs in melanocyte and melanoma biology. We summarized the regulatory mechanisms already described of lncRNAs in melanoma biology in Table 2 . There still could be other novel modes of action in IncRNAs to be identified in future.

\begin{tabular}{|l|c|}
\hline \multicolumn{1}{|c|}{ LncRNAs } & mechanisms of lncRNA \\
\hline $\begin{array}{l}\text { GAS5 [70],NUMB [71-92], PAUPAR, SAMMSON, SLNCR, ANRIL, CANT1, PVT1, HOXD-AS1, } \\
\text { MT1JP, TUSC7, LINC01260, H19, MEG3, ILF3-AS1, GAS5, RMEL3, SNHG7, } \\
\text { NEAT1,SNHG17,HAND2-AS1, SLNCR, MIAT }\end{array}$ & $\begin{array}{c}\text { Direct modulation of } \\
\text { protein-coding genes }\end{array}$ \\
\hline $\begin{array}{l}\text { UCA1 [51,55], HOXA11-AS [93], CCAT1 [94], MALAT1 [57,95], MEG3 [96], ATB [60], CASC2 } \\
\text { [33], SNHG5 [56], NEAT1 [97], TUG1 [98], ZEB1-AS1 [66], OIP5-AS1 [47], ZFAS1 [42], } \\
\text { DSCAM-AS1 [49],FOXD3-AS1 [99],MIR205HG [100], MIAT [100], (AC068594.1, C7orf71, } \\
\text { FAM41C, GPC5-AS1, MUC19, LINC00402] [101], AK077216 [61] }\end{array}$ & $\begin{array}{c}\text { Competing endogenous } \\
\text { RNA (ceRNA) for miRNA }\end{array}$ \\
\hline HMGA1 [37] & $\begin{array}{c}\text { Function as positive } \\
\text { regulator of miRNA }\end{array}$ \\
\hline LINC-PINT and BANCR [102] & $\begin{array}{c}\text { Interaction between two } \\
\text { lncRNAs }\end{array}$ \\
\hline
\end{tabular}

Table 2: The category of IncRNAs based on the regulatory mechanism in melanocyte and melanoma biology.

\section{Conclusion}

In summary, non-coding RNAs play important roles in physiology and pathology of melanocyte and melanoma. According report by the ECODE (Encyclopedia of DNA Elements) project, $76 \%$ of human genome is selectively transcribed, and only less than $3 \%$ of human genome are been translated into proteins eventually [103]. These non-coding RNAs consist of a large network that modulates gene expression at multiple levels. The noncoding RNAs mentioned above (Figure 1) are just the tip of the ice berg; the main part of it still remains under the sea. Especially, with the development of high throughput sequencing technology, i.e. whom genome sequencing (WGS), and the state of the art long reads sequencing such as PacBio and Nanopore, more and more new noncoding 


\section{International Journal of Zoology and Animal Biology}

RNAs involved in melanocyte and melanoma would be readily identified to elucidate the molecular mechanisms underlying the phenotypes of skin pigment in human and animals.

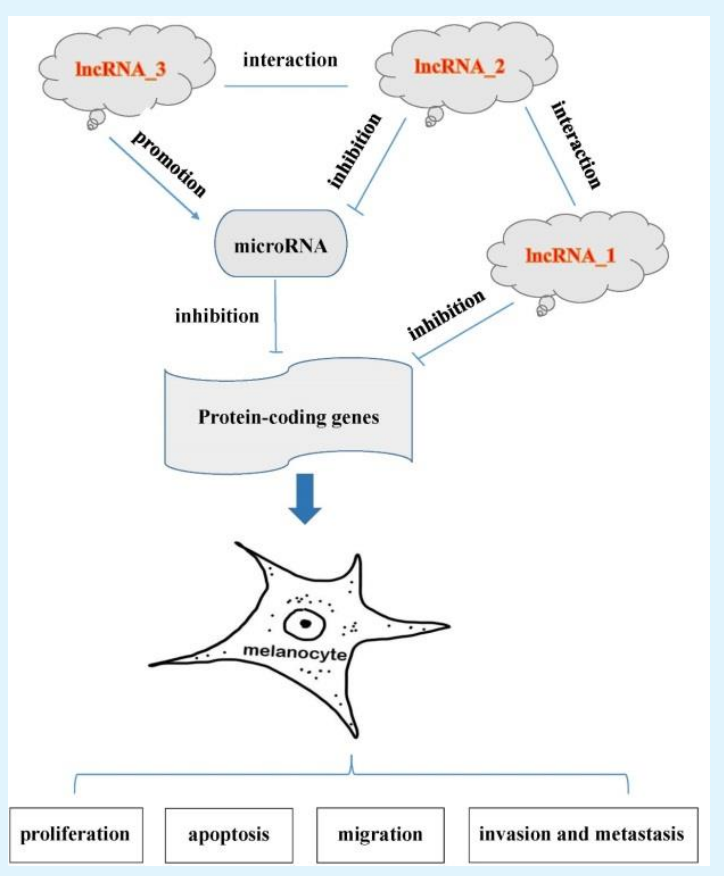

Figure 1: Sketch of the mechanisms of microRNA and lncRNA in melanocyte and melanoma.

\section{Acknowledgement}

This work was supported by the National Natural Science Foundation of China (No. 31672393), the Key R \& $\mathrm{D}$ and Transformation Project in Tibet Autonomous Region (XZ201801NB42), the Chongqing Key Science and Technology Innovation Project (cstc2017-zdyfX0045).

\section{References}

1. Lee RC, Feinbaum RL, Ambros V (1993) The C. elegans heterochronic gene lin-4 encodes small RNAs with antisense complementarity to lin-14. Cell 75(5): 843-854.

2. Wightman B, Ha I, Ruvkun G (1993) Posttranscriptional regulation of the heterochronic gene lin-14 by lin- 4 mediates temporal pattern formation in C. elegans. Cell 75(5): 855-862.
3. Ambros V (2007) The functions of animal microRNAs. Nature 431(7006): 350-355.

4. Bartel DP (2004) MicroRNAs: genomics, biogenesis, mechanism, and function. Cell 116(2): 281-297.

5. Seto AG, Kingston RE, Lau NC (2007) The coming of age for Piwi proteins. Mol Cell 26(5): 603-609.

6. Siomi MC, Sato K, Pezic D, Aravin AA (2011) PIWIinteracting small RNAs: the vanguard of genome defence. Nat Rev Mol Cell Biol 12(4): 246-258.

7. Pachnis V, Belayew A, Tilghman SM (1984) Locus unlinked to alpha-fetoprotein under the control of the murine raf and Rif genes. Proc Natl Acad Sci USA 81(17): 5523-5527.

8. Davis RL, Weintraub H, Lassar AB (1987) Expression of a single transfected cDNA converts fibroblasts to myoblasts. Cell 51(6): 987-1000.

9. Poirier F, Chan CT, Timmons PM, Robertson EJ, Evans MJ, et al. (1991) The murine H19 gene is activated during embryonic stem cell differentiation in vitro and at the time of implantation in the developing embryo. Development 113(4): 1105-1114.

10. Wutz A (2011) Gene silencing in X-chromosome inactivation: advances in understanding facultative heterochromatin formation. Nat Rev Genet 12(8): 542-553.

11. Ling H, Fabbri M, Calin GA (2013) MicroRNAs and other non-coding RNAs as targets for anticancer drug development. Nat Rev Drug Discov 12(11): 847-865.

12. Erickson CA, Reedy MV (1998) Neural crest development: the interplay between morphogenesis and cell differentiation. Curr Top Dev Biol 40: 177209.

13. Dorsky RI, Moon RT, Raible DW (1998) Control of neural crest cell fate by the Wnt signalling pathway. Nature 396(6709): 370-373.

14. Sommer L (2005) Checkpoints of melanocyte stem cell development. Sci STKE 2005(298): pe42.

15. Yamaguchi Y, Hearing VJ (2009) Physiological factors that regulate skin pigmentation. Biofactors 35(2): 193-199. 


\section{International Journal of Zoology and Animal Biology}

16. D'Mello SA, Finlay GJ, Baguley BC, Askarian Amiri ME (2016) Signaling Pathways in Melanogenesis. Int J Mol Sci 17(7).

17. Wu D, Chen JS, Chang DC, Lin SL (2008) Mir-434-5p mediates skin whitening and lightening. Clin Cosmet Investig Dermatol 1: 19-35.

18. Mione M, Bosserhoff A (2015) MicroRNAs in melanocyte and melanoma biology. Pigment Cell Melanoma Res 28(3): 340-354.

19. Mirzaei H, Gholamin S, Shahidsales S, Sahebkar A, Jaafari MR, et al. (2016) MicroRNAs as potential diagnostic and prognostic biomarkers in melanoma. Eur J Cancer 53: 25-32.

20. Ross CL, Kaushik S, Valdes Rodriguez R, Anvekar R (2018) MicroRNAs in cutaneous melanoma: Role as diagnostic and prognostic biomarkers. J Cell Physiol 233(7): 5133-5141.

21. Sahmatova L, Tankov S, Prans E, Aab A, Hermann H, et al. (2016) MicroRNA-155 is Dysregulated in the Skin of Patients with Vitiligo and Inhibits Melanogenesisassociated Genes in Melanocytes and Keratinocytes. Acta Derm Venereol 96(6): 742-747.

22. Su M, Yi H, He X, Luo L, Jiang S, et al. (2019) miR-9 regulates melanocytes adhesion and migration during vitiligo repigmentation induced by UVB treatment. Exp Cell Res 384(1): 111615.

23. Kaushik H, Malik D, Parsad D, Kaul D (2019) Mitochondrial respiration is restricted by miR-2909 within human melanocytes. Pigment Cell Melanoma Res 32(4): 584-587.

24. Zhu Z, He J, Jia X, Jiang J, Bai R, et al. (2010) MicroRNA-25 functions in regulation of pigmentation by targeting the transcription factor MITF in Alpaca (Lama pacos) skin melanocytes. Domest Anim Endocrinol 38(3): 200-209.

25. Yang S, Liu B, Ji K, Fan R, Dong C (2018) MicroRNA5110 regulates pigmentation by cotargeting melanophilin and WNT family member 1 . FASEB J 32(10): 5405-5412.

26. Yang S, Fan R, Shi Z, Ji K, Zhang J, et al. (2015) Identification of a novel microRNA important for melanogenesis in alpaca (Vicugna pacos). J Anim Sci 93(4): 1622-1631.

Song $\mathrm{T}$, et al. The Non-Coding RNAs Involved in Physiology and Pathology of Skin Melanocyte and Melanoma. Int J Zoo Animal Biol 2019, 2(6): 000188.
27. Ji K, Zhang P, Zhang J, Fan R, Liu Y, et al. (2018) MicroRNA $143-5 p$ regulates alpaca melanocyte migration, proliferation and melanogenesis. Exp Dermatol 27(2): 166-171.

28. Zhu Z, Ma Y, Li Y, Cheng Z, Li H, et al. (2019) Comparison of miRNA-101a-3p and miRNA-144a-3p regulation with the key genes of alpaca melanocyte pigmentation. BMC Mol Biol 20(1): 19.

29. Zhang Y, Bo Q, Wu W, Xu C, Yu G, et al. (2015) alphaMelanocyte-stimulating hormone prevents glutamate excitotoxicity in developing chicken retina via MC4Rmediated down-regulation of microRNA-194. Sci Rep 5: 15812 .

30. Sun W (2015) Screening and identification of microRNAs related to fetal skin melanogenesis in goat. Southwest University: Chongqing.

31. Chen C (2019) Expression Characteristics of MiR-29a in Different Tissues of Goats and Its Dynamic Expression in Melanocytes. Journal of Nuclear Agricultural Sciences.

32. Wang S, Wu Y, Xu Y, Tang X (2019) miR-10b promoted melanoma progression through Wnt/betacatenin pathway by repressing ITCH expression. Gene 710: 39-47.

33. Zhang Y, Qian W, Feng F, Cao Q Li Y (2019) Upregulated IncRNA CASC2 May Inhibit Malignant Melanoma Development Through Regulating miR18a-5p/RUNX1. Oncol Res 27(3): 371-377.

34. Wang JL, Li H, Zhang JB, Zhang CH, Hou XQ (2019) Suppression of connexin 43 expression by miR-106a promotes melanoma cell proliferation. Eur Rev Med Pharmacol Sci 23(3): 965-971.

35. Jin C, Wang A, Liu L, Wang G, Li G, et al. (2019) miR145-5p inhibits tumor occurrence and metastasis through the NF-kappaB signaling pathway by targeting TLR4 in malignant melanoma. J Cell Biochem.

36. Golan T (2019) Adipocytes sensitize melanoma cells to environmental TGF-beta cues by repressing the expression of miR-211. Sci Signal 12(591).

37. Cheng Y, Cheng T, Zhao Y, Qu Y (2019) HMGA1 exacerbates tumor progression by activating miR-222 


\section{International Journal of Zoology and Animal Biology}

through PI3K/Akt/MMP-9 signaling pathway in uveal melanoma. Cell Signal 63: 109386.

38. Prabhakar K, , Rodríguez CI, Jayanthy AS, Mikheil DM, Bhasker AI, et al. (2019) Role of miR-214 in regulation of beta-catenin and the malignant phenotype of melanoma. Mol Carcinog 58(11): 19741984.

39. Tang H, Ma M, Dai J, Cui C, Si L, et al. (2019) miR-let$7 \mathrm{~b}$ and miR-let-7c suppress tumourigenesis of human mucosal melanoma and enhance the sensitivity to chemotherapy. J Exp Clin Cancer Res 38(1): 212.

40. Zhao G, Yin Y, Zhao B (2019) miR-140-5p is negatively correlated with proliferation, invasion, and tumorigenesis in malignant melanoma by targeting SOX4 via the Wnt/beta-catenin and NF-kappaB cascades. J Cell Physiol.

41. Yang X, Zhao H, Yang J, Ma Y, Liu Z, et al. (2019) MiR150-5p regulates melanoma proliferation, invasion and metastasis via SIX1-mediated Warburg Effect. Biochem Biophys Res Commun 515(1): 85-91.

42. Liang L, Zhang Z, Qin X, Gao Y2, Zhao P, et al. (2019) Long noncoding RNA ZFAS1 promotes tumorigenesis through regulation of miR-150-5p/RAB9A in melanoma. Melanoma Res 29(6): 569-581.

43. Wang J, Fang Y, Liu YF, Wang X, Wang XL, et al. (2019) MiR-154 inhibits cells proliferation and metastasis in melanoma by targeting AURKA and serves as a novel prognostic indicator. Eur Rev Med Pharmacol Sci 23(10): 4275-4284.

44. Sun YW, Li XH, Wang H, Wu J (2019) MiR-431 is a prognostic marker and suppresses cell growth, migration and invasion by targeting NOTCH2 in melanoma. Eur Rev Med Pharmacol Sci 23(9): 38763884.

45. Peng D, Dong J, Zhao Y, Peng X, Tang J, et al. (2019) miR-142-3p suppresses uveal melanoma by targeting CDC25C, TGFbetaR1, GNAQ, WASL, and RAC1. Cancer Manag Res 11: 4729-4742.

46. Mastroianni J, Stickel N, Andrlová H, Hanke K, Melchinger W, et al. (2019) miR-146a Controls Immune Response in the Melanoma Microenvironment. Cancer Res 79(1): 183-195.

Song $\mathrm{T}$, et al. The Non-Coding RNAs Involved in Physiology and Pathology of Skin Melanocyte and Melanoma. Int J Zoo Animal Biol 2019, 2(6): 000188.
47. Luan W, Zhang X, Ruan H, Wang J, Bu X (2019) Long noncoding RNA OIP5-AS1 acts as a competing endogenous RNA to promote glutamine catabolism and malignant melanoma growth by sponging miR217. J Cell Physiol.

48. Li J, Liu X, Li C, Wang W (2019) miR-224-5p inhibits proliferation, migration, and invasion by targeting PIK3R3/AKT3 in uveal melanoma. J Cell Biochem 120(8): 12412-12421.

49. Huang YL, Xu Q, Wang X (2019) Long noncoding RNA DSCAM-AS1 is associated with poor clinical prognosis and contributes to melanoma development by sponging miR-136. Eur Rev Med Pharmacol Sci 23(7): 2888-2897.

50. Hu Y, Wang Q, Zhu XH (2019) MiR-135b is a novel oncogenic factor in cutaneous melanoma by targeting LATS2. Melanoma Res 29(2): 119-125.

51. Han C, Tang F, Chen J, Xu D, Li X, et al. (2019) Knockdown of IncRNA-UCA1 inhibits the proliferation and migration of melanoma cells through modulating the miR-28-5p/HOXB3 axis. Exp Ther Med 17(5): 4294-4302.

52. Han Y, Li X, Ma C, Ji X, Li T, et al. (2019) Seed targeting with tiny anti-miR-1297 inhibits EMT in melanoma cells. J Drug Target 27(1): 75-81.

53. DiSano JA, Huffnagle I, Gowda R, Spiegelman VS, Robertson GP, et al. (2019) Loss of miR-155 upregulates WEE1 in metastatic melanoma. Melanoma Res 29(2): 216-219.

54. Caporali S, Amaro A, Levati L, Alvino E, Lacal PM, et al. (2019) miR-126-3p down-regulation contributes to dabrafenib acquired resistance in melanoma by upregulating ADAM9 and VEGF-A. J Exp Clin Cancer Res 38(1): 272.

55. Wei $Y$, Sun $Q$, Zhao L, Wu J, Chen X, et al. (2016) LncRNA UCA1-miR-507-FOXM1 axis is involved in cell proliferation, invasion and G0/G1 cell cycle arrest in melanoma. Med Oncol 33(8): 88.

56. Gao J, Zeng K, Liu Y, Gao L, Liu L (2018) LncRNA SNHG5 promotes growth and invasion in melanoma by regulating the miR-26a-5p/TRPC3 pathway. Onco Targets Ther 12: 169-179. 


\section{International Journal of Zoology and Animal Biology}

57. Li F, Li X, Qiao L, Liu W, Xu C, et al. (2019) MALAT1 regulates miR-34a expression in melanoma cells. Cell Death Dis 10(6): 389.

58. Pedini F, De Luca G, Felicetti F, Puglisi R, Boe A, et al. (2019) Joint action of miR-126 and MAPK/PI3K inhibitors against metastatic melanoma. Mol Oncol 13(9): 1836-1854.

59. Li J, Chen J, Wang S, Li P, Zheng C, et al. (2019) Blockage of transferred exosome-shuttled miR-494 inhibits melanoma growth and metastasis. J Cell Physiol.

60. Mou K, Liu B, Ding M, Mu X, Han D, et al. (2018) IncRNA-ATB functions as a competing endogenous RNA to promote YAP1 by sponging miR-590-5p in malignant melanoma. Int J Oncol 53(3): 1094-1104.

61. Zhang X, Shi E, Yang L, Fu W, Hu F, et al. (2019) LncRNA AK077216 is downregulated in diabetic retinopathy and inhibited the apoptosis of retinal pigment epithelial cells by downregulating miR-383. Endocr J 66(11): 1011-1016.

62. Chai L, Kang XJ, Sun ZZ, Zeng MF, Yu SR, et al. (2018) MiR-497-5p, miR-195-5p and miR-455-3p function as tumor suppressors by targeting hTERT in melanoma A375 cells. Cancer Manag Res 10: 989-1003.

63. Datar I, Kalpana G, Choi J, Basuroy T, Trumbly R, et al. (2019) Critical role of miR-10b in B-RafV600E dependent anchorage independent growth and invasion of melanoma cells. PLoS One 14(4): e0204387.

64. Desjobert C, Carrier A, Delmas A, Marzese DM, Daunay A, et al. (2019) Demethylation by low-dose 5aza-2'-deoxycytidine impairs 3D melanoma invasion partially through miR-199a-3p expression revealing the role of this miR in melanoma. Clin Epigenetics 11(1): 9.

65. Byrnes CC, Jia W, Alshamrani AA, Kuppa SS, Murph $M M$, et al. (2019) miR-122-5p Expression and Secretion in Melanoma Cells Is Amplified by the LPAR3 SH3-Binding Domain to Regulate Wnt1. Mol Cancer Res 17(1): 299-309.

66. Wang Q, Zhang R, Liu D (2019) Long non-coding RNA ZEB1-AS1 indicates poor prognosis and promotes

Song $\mathrm{T}$, et al. The Non-Coding RNAs Involved in Physiology and Pathology of Skin Melanocyte and Melanoma. Int J Zoo Animal Biol 2019, 2(6): 000188. melanoma progression through targeting miR-12245p. Exp Ther Med 17(1): 857-862.

67. Chen Y, Cao K, Li J, Wang A, Sun L, et al. (2019) Overexpression of long non-coding RNA NORAD promotes invasion and migration in malignant melanoma via regulating the MIR-205-EGLN2 pathway. Cancer Med 8(4): 1744-1754.

68. Zhang H, Feng C, Zhang M, Zeng A, Si L, et al. (2019) miR-625-5p/PKM2 negatively regulates melanoma glycolysis state. J Cell Biochem 120(3): 2964-2972.

69. Ren H, Wang G, Chen L, Jiang J, Liu L, et al. (2016) Genome-wide analysis of long non-coding RNAs at early stage of skin pigmentation in goats (Capra hircus). BMC Genomics 17(1): 67.

70. Chen L, Yang H, Xiao Y, Tang X, Yuqian Li, et al. (2016) LncRNA GAS5 is a critical regulator of metastasis phenotype of melanoma cells and inhibits tumor growth in vivo. Onco Targets Ther 9: 4075-4087.

71. Cheng G, He J, Zhang L, Ge S, Zhang H, et al. (2016) HIC1 modulates uveal melanoma progression by activating lncRNA-numb. Tumour Biol 37(9): 1277912789.

72. Ding X, Wang X, Lin M, Xing Y, Ge S, et al. (2016) PAUPAR IncRNA suppresses tumourigenesis by H3K4 demethylation in uveal melanoma. FEBS Lett 590(12): 1729-1738.

73. Leucci E, Vendramin R, Marco S, Laurette P, Fiers M, et al. (2016) Melanoma addiction to the long noncoding RNA SAMMSON. Nature 531(7595): 518-522.

74. Schmidt K, Joyce CE, Buquicchio F, Brown A, Ritz J, et al. (2016) The lncRNA SLNCR1 Mediates Melanoma Invasion through a Conserved SRA1-like Region. Cell Rep 15(9): 2025-2037.

75. Xu S, Wang H, Pan H, Shi Y, Li T, et al. (2016) ANRIL IncRNA triggers efficient therapeutic efficacy by reprogramming the aberrant INK4-hub in melanoma. Cancer Lett 381(1): 41-48.

76. Xing Y, Wen X, Ding X, Fan J, Chai P, et al. (2017) CANT1 lncRNA Triggers Efficient Therapeutic Efficacy by Correcting Aberrant Incing Cascade in Malignant Uveal Melanoma. Mol Ther 25(5): 1209-1221. 


\section{International Journal of Zoology and Animal Biology}

77. Xu H, Gong J, Liu H (2017) High expression of IncRNA PVT1 independently predicts poor overall survival in patients with primary uveal melanoma. PLoS One 12(12): e0189675.

78. Zhang H, Bai M, Zeng A, Loubin Si, Nanze Yu, et al. (2017) LncRNA HOXD-AS1 promotes melanoma cell proliferation and invasion by suppressing RUNX3 expression. Am J Cancer Res 7(12): 2526-2535.

79. Qi H, X Su (2017) Effects of LncRNA MT1JP on migration and invasion of uveal melanoma cells. Recent Advances in Ophthalmology 37(6): 531-534.

80. Yuan Z (2017) Expression of lnc RNA TUSC7 in melanoma A375 cell line and its effect on proliferation and apoptosis of melanoma cells. Chinese Journal of Clinical and Experimental Pathology 33(4).

81. Ma X, He Z, Li L, Yang D, Liu G, et al. (2017) Expression profiles analysis of long non-coding RNAs identified novel lncRNA biomarkers with predictive value in outcome of cutaneous melanoma. Oncotarget 8(44): 77761-77770.

82. Liao Z, Zhao J, Yang Y (2018) Downregulation of lncRNA H19 inhibits the migration and invasion of melanoma cells by inactivating the NFkappaB and PI3K/Akt signaling pathways. Mol Med Rep 17(5): 7313-7318.

83. Li P, Gao Y, Li J, Zhou Y, Yuan J, et al. (2018) LncRNA MEG3 repressed malignant melanoma progression via inactivating Wnt signaling pathway. J Cell Biochem 119(9): 7498-7505.

84. Gao G, Wenjun Li, Sha Liu, Dongmei Han, Xingwei Yao, et al. (2018) The positive feedback loop between ILF3 and IncRNA ILF3-AS1 promotes melanoma proliferation, migration, and invasion. Cancer Manag Res 10: 6791-6802.

85. Chen L, Yang H, Yi Z, Jiang L, Li Y, et al. (2019) LncRNA GAS5 regulates redox balance and dysregulates the cell cycle and apoptosis in malignant melanoma cells. J Cancer Res Clin Oncol 145(3): 637652.

86. Cardoso C, Serafim RB, Kawakami A, Pereira C, Roszik J, et al. (2019) The IncRNA RMEL3 protects immortalized cells from serum withdrawal-induced growth arrest and promotes melanoma cell proliferation and tumor growth. Pigment Cell Melanoma Res 32(2): 303-314.

87. Zhang C, Zhu B, Li XB, Cao YQ, Yang JC, et al. (2019) Long non-coding RNA SNHG7 promotes migration and invasion of melanoma via upregulating SOX4. Eur Rev Med Pharmacol Sci 23(11): 4828-4834.

88. He J, Xu F, Man X, Zhang Y, Li H, et al. (2019) Long non-coding RNA NEAT1 promotes tumor development and metastasis through targeting RAB9A in malignant melanoma. Minerva Med.

89. Gao H, Liu R, Sun X (2019) STAT3-induced upregulation of IncRNA SNHG17 predicts a poor prognosis of melanoma and promotes cell proliferation and metastasis through regulating PI3KAKT pathway. Eur Rev Med Pharmacol Sci 23(18): 8000-8010.

90. Liu P, Du R, Yu X (2019) LncRNA HAND2-AS1 overexpression inhibits cancer cell proliferation in melanoma by downregulating ROCK1. Oncol Lett 18(2): 1005-1010.

91. Schmidt K, Carroll JS, Yee E, Thomas DD, Wert Lamas L, et al. (2019) The IncRNA SLNCR Recruits the Androgen Receptor to EGR1-Bound Genes in Melanoma and Inhibits Expression of Tumor Suppressor p21. Cell Rep 27(8): 2493-2507.

92. Yang Y, Zhang Z, Wu Z, Lin W, Yu M (2019) Down regulation of the expression of the lncRNA MIAT inhibits melanoma migration and invasion through the PI3K/AKT signaling pathway. Cancer Biomark 24(2): 203-211.

93. Lu Q, Zhao N, Zha G, Wang H, Tong Q, et al. (2017) LncRNA HOXA11-AS Exerts Oncogenic Functions by Repressing p21 and miR-124 in Uveal Melanoma. DNA Cell Biol 36(10): 837-844.

94. Lv L, Jia JQ, Chen J (2018) The IncRNA CCAT1 Upregulates Proliferation and Invasion in Melanoma Cells via Suppressing miR-33a. Oncol Res 26(2): 201208.

95. Sun Y, Cheng H, Wang G, Yu G, Zhang D, et al. (2017) Deregulation of miR-183 promotes melanoma development via lncRNA MALAT1 regulation and ITGB1 signal activation. Oncotarget 8(2): 3509-3518. 
96. Long J, Pi X (2018) lncRNA-MEG3 Suppresses the Proliferation and Invasion of Melanoma by Regulating CYLD Expression Mediated by Sponging miR-499-5p. Biomed Res Int pp: 2086564.

97. Xia Y, Zhou Y, Han H, Li P, Wei W, et al. (2019) lncRNA NEAT1 facilitates melanoma cell proliferation, migration, and invasion via regulating miR-495-3p and E2F3. J Cell Physiol 234(11): 19592-19601.

98. Wang Y (2019) Long non-coding RNA TUG1 recruits miR29c3p from its target gene RGS1 to promote proliferation and metastasis of melanoma cells. Int J Oncol 54(4): 1317-1326.

99. Chen X, Gao J, Yu Y, Zhao Z, Pan Y (2019) LncRNA FOXD3-AS1 promotes proliferation, invasion and migration of cutaneous malignant melanoma via regulating miR-325/MAP3K2. Biomed Pharmaco ther 120: 109438.
100. Liu N, Liu Z, Liu X, Chen H ( 2019) Comprehensive Analysis of a Competing Endogenous RNA Network Identifies Seven-lncRNA Signature as a Prognostic Biomarker for Melanoma. Front Oncol 9: 935.

101. Wang LX, Wan C, Dong ZB, Wang BH, Liu HY, et al. (2019) Integrative Analysis of Long Noncoding RNA (lncRNA), microRNA (miRNA) and mRNA Expression and Construction of a Competing Endogenous RNA (ceRNA) Network in Metastatic Melanoma. Med Sci Monit 25: 2896-2907.

102. Huang Q, Zhang D, Diao Q, Lin M (2019) IncRNA LINC-PINT is downregulated in melanoma and regulates cell proliferation by downregulating lncRNA BANCR. Oncol Lett 18(3): 2917-2922.

103. Pennisi E (2012) Genomics. ENCODE project writes eulogy for junk DNA. Science 337(6099): 1159-1161. 